\title{
Laboreal
}

Volume $17 \mathrm{~N}^{\circ} 1$ | 2021

Trabalhar hoje: mudanças, permanências, estratégias, reinvenções

\section{Dinâmica psicológica e trabalho de profissionais de saúde no Brasil durante a pandemia de COVID-19 : colaborando para compreender $\leftrightarrow$ transformar sua experiência}

Dinámica psicológica y trabajo de los profesionales de la salud en Brasil durante la pandemia de COVID-19 : contribuyendo a comprender $\leftrightarrow$ transformar su experiencia

Dynamique psychologique et travail des professionnels de la santé au Brésil pendant la pandémie COVID-19: collaborer pour comprendres $\triangleleft$ transformer son expérience

Psychological dynamics and work of health professionals in Brazil during the COVID-19 Pandemic: contributing to comprehend $\leftrightarrow$ transform their experience

\section{Wladimir Ferreira de Souza e Milton Athayde}

\section{(2) OpenEdition}

\section{Journals}

\section{Edição electrónica}

URL: https://journals.openedition.org/laboreal/17673

DOI: 10.4000/laboreal.17673

ISSN: 1646-5237

\section{Editora}

Universidade do Porto

\section{Refêrencia eletrónica}

Wladimir Ferreira de Souza e Milton Athayde, «Dinâmica psicológica e trabalho de profissionais de saúde no Brasil durante a pandemia de COVID-19 : colaborando para compreender $\leftrightarrow$ transformar sua experiência», Laboreal [Online], Volume $17 \mathrm{~N}^{0} 1$ | 2021, posto online no dia 18 junho 2021, consultado o 20 junho 2021. URL: http://journals.openedition.org/laboreal/17673 ; DOl: https://doi.org/10.4000/ laboreal. 17673

Este documento foi criado de forma automática no dia 20 junho 2021.

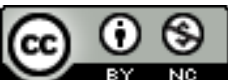

Laboreal está licenciado com uma Licença Creative Commons - Atribuição-NãoComercial 4.0 Internacional. 


\section{Dinâmica psicológica e trabalho de profissionais de saúde no Brasil durante a pandemia de COVID-19 : colaborando para compreender $\leftrightarrow$ transformar sua experiência}

Dinámica psicológica y trabajo de los profesionales de la salud en Brasil durante la pandemia de COVID-19: contribuyendo a comprender $\leftrightarrow$ transformar su experiencia

Dynamique psychologique et travail des professionnels de la santé au Brésil pendant la pandémie COVID-19: collaborer pour comprendre $\leftrightarrow$ transformer son expérience

Psychological dynamics and work of health professionals in Brazil during the COVID-19 Pandemic: contributing to comprehend $\leftrightarrow$ transform their experience Wladimir Ferreira de Souza e Milton Athayde

\section{NOTA DO EDITOR}

Manuscrito recebido em : 03/01/2021

Aceite após peritagem em : 07/04/2021 


\section{Introdução}

1 O objetivo geral do artigo é apresentar uma análise inicial de questões referentes ao trabalho em Saúde [1] no Brasil, no contexto - surpreendente e dramático - da pandemia da COVID-19, sobre a qual pouco ainda se sabe, em todos os planos. Pretendese, em especial, contribuir para um debate acerca das relações entre os processos de trabalho, a dinâmica psicológica aí em curso e a luta pela saúde. 0 objetivo específico está no exame de uma questão que foi selecionada a partir de uma experimentação que vem sendo desenvolvida no âmbito da "Extensão Universitária" - ExtUniv (sob a coordenação dos dois autores do artigo). Coloca-se também para análise um referencial da Psicologia do Trabalho e Organizacional que foi mobilizado e que é norteado pelo chamado ponto de vista da atividade (Brito, 2005) e da experiência (Diallo, \& Clot, 2003).

2 Nesta linhagem, o trabalhar (Dejours, 2004) é aqui entendido como experiência constitutiva de nossa espécie e atividade subjetivante, estruturante do psiquismo humano. Nesta medida se articulam o macro (o mundo social) e o micro (o singular), sendo operador de sentido e de busca de saúde (mental). Tendo como base a descoberta central da Ergonomia da Atividade (Guérin, Laville, Daniellou, Duraffourg, \& Kerguelen, 2001) - a defasagem sempre existente entre tarefa e atividade -, Christophe Dejours, na abordagem Psicodinâmica do Trabalho, avança em sua compreensão no plano psicológico e afirma :

\footnotetext{
“Trabalhar é preencher a lacuna entre o prescrito e o real [...], aquilo que o sujeito deve acrescentar às prescrições para poder atingir os objetivos que lhe são designados; ou ainda aquilo que ele deve acrescentar de si mesmo para enfrentar o que não funciona quando ele se atém escrupulosamente à execução das prescrições" (Dejours, 2004, p. 28).
}

3 O mesmo autor, em seguida, intervém com o conceito de "real do trabalho", designando o que se revela afetivamente, na forma de sofrimento (nesta abordagem entendido como pathos, capacidade de ser afetado pelo real), pois no curso do trabalhar algo sempre escapa à maestria, levando a uma experiência de revés (e mesmo de fracasso) frente aos equívocos da prescrição, às variabilidades e ao acaso. Nesse sentido há, para quem trabalha, uma relação de sofrimento (que pode ou não tomar um rumo patogênico) em sua dinâmica psicológica com o trabalho.

4 Neste artigo, a atenção de fundo está na experiência vivida e relatada por profissionais de saúde (ou seja, da área da Saúde) que, na rede de atendimento, estão atuando na chamada "linha de frente" (ou no apoio institucional ou técnico aos que lá estão), em sua maioria mulheres, a quem geralmente são social e historicamente atribuídas também as responsabilidades pelo trabalho doméstico (Hirata, 2002), questão à qual o artigo retornará.

5 Em um primeiro momento apresentamos o quadro de emergência internacional da COVID-19 e as características gerais das situações de trabalho que vêm sendo enfrentadas pelos profissionais de saúde mais envolvidos com a pandemia no Brasil. Em seguida, foi selecionado um alvo para exame a partir de pistas que emergiram da prática de ExtUniv (considerando o tripé universitário Ensino-Pesquisa-Extensão), que vem sendo desenvolvida sob a coordenação dos dois autores do artigo, contando com a participação de diferentes tipos de atores (profissionais e estudantes). As ações de ExtUniv vêm se dando na parceria de uma Universidade pública do estado com um 
Centro de Referência em Saúde do Trabalhador (CEREST) também do estado do Rio de Janeiro.

6 A análise mobilizou diferentes ferramentas, seja da epistemologia ergológica (Schwartz, 2007/2010), seja de algumas das abordagens da Clínica do Trabalho (Clot \& Lhuilier, 2013), averiguando-se também sua pertinência analítica.

\section{COVID-19, a pandemia}

7 A COVID-19 (coronavirus disease-19), é a denominação da doença causada pelo SARSCoV-2, um novo agente descoberto, pertencente a uma família de vírus que causam infecções respiratórias. Os primeiros casos foram detectados no final de 2019. Em janeiro de 2020, a Organização Mundial da Saúde (OMS) declarou que o surto de COVID-19 representava uma Emergência de Saúde Pública de Importância Internacional. Segundo a OMS havia já naquele momento um alto risco de que esta doença tomasse proporções pandêmicas, espalhando-se praticamente por todo o mundo. Tal temor se confirmou e, já em março de 2020, afirmava-se que a COVID-19 podia ser caracterizada como pandemia. Desde então, autoridades de Saúde Pública de todo o planeta estão agindo, de formas diferenciadas, para tentar conter o surto da doença. Configura-se então uma crise geradora de tormento em toda a população, principalmente nos profissionais de saúde que estão na chamada "linha de frente" da luta contra o vírus.

8 No Brasil, em março de 2020, as autoridades decretaram situação de emergência, na tentativa de contenção do contágio e do surto da doença. Um processo que vem se dando em um quadro conturbado de ações, sem unidade e integração de esforços nos diversos níveis governamentais. 0 mais evidente e lamentável para todos passou a ser a forma muitas vezes antagônica e litigante, como os governos, nos diversos níveis federal, estadual e municipal- vêm tomando suas respectivas posições e medidas de enfrentamento desse grave problema.

Quanto ao quadro de governabilidade operada ao nível central, a marca tem sido a da chamada ideologia negacionista, o que se tornou ostensivo com a demissão do primeiro ministro da Saúde do atual governo (após cerca de 16 meses no cargo), seguida, em cerca de um mês, do pedido de demissão de seu sucessor, ambos médicos. Para sua sucessão, não conseguindo o presidente da República um profissional de saúde que seguisse estritamente sua concepção negacionista, sua opção foi pôr um punhado de militares na equipe ministerial, sem longa experiência e autoridade no campo da Saúde Pública, comandados por um general, que declarou recentemente que, antes de assumir o Ministério da Saúde (MS), não sabia o que era o SUS [2]. Já 5 meses após sua posse, o general-ministro foi publicamente desautorizado pelo presidente, após declarar que o MS assinaria um protocolo de intenções para adquirir 46 milhões de doses da vacina CoronaVac de uma empresa chinesa, que tem no Brasil a colaboração com o Instituto Butantan de São Paulo. Por razões político-ideológicas e não científicas, o presidente afirmou que não compraria a "vacina chinesa" e voltou a defender o uso da hidroxicloroquina (droga cuja eficácia não tem qualquer evidência científica para tratamento da COVID-19). 
10 Cabe registrar que no final de fevereiro de 2021 os números da COVID-19 no Brasil registravam mais de 10,5 milhões de pessoas infectadas e mais de 254 mil óbitos. Até então o pior momento, desde o início da Pandemia.

11 É neste confuso e complexo cenário político-social e jurídico (além do econômico), em que governantes desrespeitam as recomendações da OMS e tomam medidas irresponsáveis, que os profissionais de saúde estão atuando e se desdobrando. E é exatamente em tal cenário que os autores do artigo tomaram suas decisões éticoprofissionais e se definiram por um método de intervenção, o qual será descrito a seguir.

12 Um exemplo do contexto degradante, que extrapola a pandemia, mas que também se refere ao descaso com a Saúde Pública no Brasil, ocorreu no Rio de Janeiro em outubro de 2020, quando o Hospital Federal de Bonsucesso, maior hospital público do estado (com mais de 5000 trabalhadores, 600 leitos - dos quais 300 estavam em uso), foi abatido por um incêndio, 72 anos após sua inauguração. Uma desgraça anunciada por diversos documentos oficiais, sem que há anos qualquer providência fosse tomada. Sequer permissão do Corpo de Bombeiros havia, como não existe para diversos outros grandes hospitais... Dois dias depois quatro usuários internados já haviam morrido, aumentando o número no decorrer dos dias. A primeira foi exatamente uma enfermeira do setor de radiologia de outro hospital público, internada com COVID-19. Enfim, um cenário em que profissionais de saúde estão sendo atingidos por todos os lados... Quanto aos autores do artigo, também profissionais de saúde, (além de docentes, pesquisadores), encontram-se em outro lugar de atuação, e viram-se frente à questão : o que fazer ? Como contribuir no processo?

\section{A propósito do método}

13 Frente a tantos absurdos, já históricos, a emergência da pandemia no Brasil levou muito rapidamente a um quadro trágico e dramático, com triste colorido, mobilizando, de diferentes formas, a todos. Assim, a escolha ética e metodológica dos autores se deu "no calor do momento", sob influência de tal contexto crítico. O contato com profissionais de saúde e algumas de suas solicitações, por intermédio das ações do já referido projeto de ExtUniv, agiram como força de convocação de nossos saberes, cuja validação para aquela situação singular, dependeria da aceitação e do sucesso (mesmo que relativo) de nosso encaminhamento metodológico. Assim, nosso engajamento e valores foram intensamente mobilizados, guiando a tomada de decisão também quanto ao método para acompanhar o processo em curso.

14 À neutralidade impossível responde-se com a explicitação da implicação, como vem sendo reiterada. Diversas linhagens têm colocado em questão a neutralidade na produção de conhecimento, em Psicologia, como o faz a Análise Institucional, com a figura do chamado intelectual implicado. E também em outros continentes científicos, podendo-se destacar a figura do Nobel de Química Ilya Prigogine (2009), que dá relevância ao papel desempenhado pela paixão na produção de conhecimento. Antes disso, já Gramsci (2000) registrara a importância do sentir e se apaixonar na formação da figura que conceitua por "intelectual orgânico".

15 A implicação no processo na intervenção e na investigação pode também ser designada como "afinidade eletiva", com base no remanejamento feito por Michel Löwy em 
relação à concepção de Max Weber. $\mathrm{O}$ uso da referida noção visa registrar a presença de uma urgente demanda social, gerando uma sinergia entre os acontecimentos pandêmicos e os valores vividos pelos autores do artigo, assim como por outros atores pertinentes a esses acontecimentos - no caso, os profissionais de saúde. Em certa medida, resguardadas as diferenças históricas e epistemológicas, a mobilização gerada nos autores tem a ver com o que o mesmo Löwy (2005) registrou acerca da posição de Walter Benjamin : o "escovar a história a contrapelo". Sim, de algum modo, "o ponto de vista dos vencidos" está sendo, mais uma vez, o das classes populares (no interior das quais se encontram os profissionais de saúde), considerando a proveniência e emergência da pandemia no Brasil. É sobre elas que as inaceitáveis condições de vida - sanitárias (em geral, não só de ausência de rede de água e esgoto), de trabalho, de deslocamento em transportes de massa, etc., rebatem com violência.

O alvo analítico, em última instância, está nas categorias profissionais de saúde que ora se encontram "na linha de frente" e no apoio direto a estes, na luta pela vida, frente à pandemia e seus efeitos. $\mathrm{Na}$ atual crise, os autores têm buscado colaborar, dentro de suas possibilidades, com tais parceiros profissionais, visando melhor compreender $\leftrightarrow$ transformar - mesmo que no ínfimo - o dramático cenário em que estão eles vivendo e trabalhando. $\mathrm{E}$ atentos à potência da experiência e cultura que podem estar sendo engendradas no curso dos acontecimentos. O foco está nos relatos das vivências sobre o trabalho, obtidos a partir das Conversas e Encontros que se desenvolveram, por meio eletrônico, no curso da já referida ExtUniv.

Foram também compulsados dois documentos científicos que corroboraram as análises aqui presentes : um com recomendações e orientações (Noal, Passos, \& Freitas, 2020); o outro um dossiê organizado por Amarante, Amorim, Silva, Guljor e Machado (2020), enfocando a saúde mental.

o foco está na escuta da vivência dos trabalhadores em questão, malgrado a distância objetiva gerada pelo respeito ao princípio do afastamento, para evitar o contágio. Obstáculo que poderia ter sido fator de impedimento do curso da investigação empreendida, mas optou-se por aceitar a pertinência dos materiais disponíveis, assim engajando-se e contribuindo na luta coletiva pela saúde.

20 A estratégia metodológica então considerada viável e consequente foi a de dar um passo inicial investigando de forma exploratória e qualitativa os materiais emergentes da prática de ExtUniv. A sondagem envolveu trocas virtuais e o diálogo remoto com os grupos profissionais citados, o que nos mobilizou inicialmente a produzir um material similar a uma Cartilha, destinado aos profissionais de saúde (Souza et al., 2020).

21 Cabe nesse ponto lembrar que as ações de ExtUniv vêm se dando na parceria de uma Universidade pública do estado com um Centro de Referência em Saúde do Trabalhador (CEREST) também do estado do Rio de Janeiro. Os CEREST são unidades de saúde consideradas dispositivos estratégicos para a consolidação da Política Nacional de Saúde do Trabalhador e da Trabalhadora, a qual fica a cargo do Sistema Único de Saúde (SUS) no Brasil. $O$ território de abrangência do referido CEREST compreende quatro municípios.

Quanto à proposta contemporânea de ExtUniv, suas características, com frequência, não são efetivamente conhecidas. Ela surgiu no meado do século XIX no Reino Unido, primeiro como "educação continuada", em seguida como "estudos extramurais" (ou seja, destinada à população adulta que não tinha acesso à Universidade). Já no Brasil 
(Gadotti, 2017), foi no início da década de 1960 que a concepção contemporânea de ExtUniv passou a ser entendida em sua relação indissociável com o ensino e a pesquisa. Porém naquele momento histórico encorpando-se em uma conjuntura em que se pretendia agir em um compromisso com as classes populares, visando "conscientizálas" sobre seus direitos.

Só nos anos 1980, período de "redemocratização", de importantes mudanças no país, uma concepção forte de ExtUniv se estruturou. Em 1987 foi criado o "Fórum de PróReitores de Extensão das Instituições de Educação Superior Públicas Brasileiras", definindo-se a ExtUniv como um processo - educativo, cultural e científico -, articulando o Ensino e a Pesquisa de forma indissociável, que teria o potencial de estabelecer uma relação transformadora entre Universidade e Sociedade. A riqueza dessa conquista foi patrimonializada na Constituição de 1988, consagrando (Artigo 207) o princípio da "indissociabilidade entre ensino, pesquisa e extensão". Já em 1996 a Lei 9.394/96 (Artigo 43) estabeleceu a ExtUniv como uma das finalidades da Universidade.

A história da ExtUniv revela em seu processo duas vertentes, que têm se contraposto. Uma denomina-se extensionista, assistencialista, de transmissão vertical do conhecimento, em uma via de mão única, da Universidade para a sociedade, ignorando a cultura e o saber popular. Outra - propondo uma via de "mão dupla" - foi definida pelo Plano Nacional de Extensão Universitária, como de co-participação dos sujeitos no ato de conhecer.

25 A proveniência desta visão contemporânea, não assistencialista, que recusa a limitada aplicação do saber acadêmico-científico, remete às práticas de Paulo Freire no Nordeste, anos 1950-60. Sendo expulso do Brasil pela ditadura civil-militar, Freire (1968/2013) teve a oportunidade de refletir sobre suas proposições e práticas, o que se pode encontrar em diversos de seus livros. Dentre os remanejamentos por ele efetuados, em seu livro a noção de Extensão foi então substituída pela de Comunicação, pois para ele os seres humanos são fundamentalmente comunicativos, seres de transformação do mundo. Configura-se então a ExtUniv como comunicação de saberes, uma forma de Extensão dialógica, entrelaçando saberes populares e conhecimentos acadêmico-científicos.

Nosso norte tem sido então o ponto de vista da atividade de trabalho e o estabelecimento de uma modalidade de "dispositivo dinâmico de três polos" - DD3P, como em Ergologia se designa um dado regime de produção de saberes e transformações, na dialogia entre diferentes saberes (polos 1 e 2), sustentada por uma relação ética e epistêmica (terceiro polo). Schwartz (2007/2010) esclarece que se trata de uma consequência direta da potencialidade humana de produzir novas normas em um meio - normatividade vital nas palavras de Canguilhem, renormatização nas de Schwartz - no curso mesmo da atividade. Esta qualidade ativa dos humanos frente ao que emerge na vida e no trabalho tem seu fundamento na obra de Georges Canguilhem, quando desenvolve o caráter filosófico das Ciências da Vida (Canguilhem, 1977). Schwartz, além da assumida influência da obra de Canguilhem, recorre também à Ergonomia da Atividade (Guérin et al., 2001) e ao patrimônio gerado pela ação do Modelo Operário Italiano de luta pela saúde e produção de conhecimento - MOI (Oddone et al., 2020). No âmbito do MOI se desenvolveu o dispositivo Comunidade Científica Ampliada (CCA) e então Schwartz assenta que o DD3P foi proposto buscando superar o que ele entendeu como limites e contradições presentes no conceito de CCA (Schwartz, 2000). É neste debate que no Brasil foram reconfigurados tais conceitos, e 
construído o de "Comunidade Ampliada de Pesquisa $\leftrightarrow$ Intervenção" - CAPI (Brito \& Athayde, 2020).

Conforme a démarche ergológica, a intervenção se sustenta no desenvolvimento sistemático de Encontros sobre o Trabalho (EsT) com os sujeitos - uma modalidade/ configuração do DD3P (Durrive, 2007/2010 ; Masson, Gomes \& Brito, 2015) -, quando se estabelecem Conversas sobre o Trabalho (CsT).

\section{Os profissionais de saúde na "linha de frente" e suas vicissitudes}

Os profissionais de saúde vêm enfrentando no Brasil, historicamente, dificuldades importantes, dada a realidade sanitária brasileira, dentre elas o quadro cronicamente combalido do SUS. E, frente a tais desafios, durante a pandemia, novas dificuldades no momento vêm sendo engendradas.

A respeito da questão, o material dialógico engendrado no curso da prática de ExtUniv, assim como os materiais anteriormente referidos (Noal et al., 2020, Souza et al., 2020), indicaram a presença de uma espiral descendente que combina: relações entre situações de trabalho ainda mais precarizadas que o habitual com novas exigências (intensas e de rapidíssima geração), potencializando nocivamente a já elevada tensão e alta vulnerabilidade. Ou seja, um quadro propício à emergência do que a abordagem Psicodinâmica do Trabalho (Dejours, 2012a, 2012b) considera sofrimento psíquico de tipo patogênico. Nas narrativas que têm emergido no curso das referidas ações advém um conjunto de experiências vividas relatadas, envolvendo : (i) sobrecarga de trabalho, sistematicamente ficando em estado de alerta intenso, com grandes dificuldades para lidar com a alta demanda de atendimento, gerando intenso e crônico desgaste físico e emocional ; (ii) um quadro agravado por novas incertezas, que vêm gerando inéditas formas de insegurança e medo; (iii) insólitas modalidades de insatisfação no ambiente de trabalho, inclusive por ameaças e violências, veladas ou explícitas, verbais ou mesmo físicas ; (iv) temor de serem infectadas(os) e transmitirem o vírus para seus familiares, pairando mesmo a dúvida se poderão revê-los. A estas agruras somam-se vivências de desamparo (seja por ruptura de contrato de trabalho, com falta de pagamento de salário, seja por exclusão social, dado serem percebidos como profissionalmente relacionados ao vírus), tédio e solidão (seja pelo distanciamento dos familiares e amigos, devido à quarentena, seja pela falta de suporte técnico e fragilização do coletivo de trabalho), com sensação de impotência perante os acontecimentos (percepção de não respeito rigoroso dos protocolos de biossegurança), associadas à irritabilidade e tristeza (até mesmo por sentirem suas próprias dificuldades de ajuste aos rigores dos novos protocolos).

Foram comentados casos de profissionais que passaram a morar provisoriamente fora de seus lares, o que pode contribuir para o aumento da solidão, da insegurança e do medo, pela falta de contato, diálogo e suporte social, seja dos familiares, dos colegas de trabalho ou de outras de redes de apoio.

31 Não obstante, por sua importância, persistência e resistência, os profissionais de saúde, em especial os da linha de frente, parecem estar conseguindo obter maior visibilidade e reconhecimento nesse momento, chegando a ser alçados na mídia ao status de heróis. Porém essa moeda tem dois lados. Ao mesmo tempo em que são, de certo modo, 
valorizados, convive-se nesse ofício com a precariedade, faltando muito ainda para obterem o devido e efetivo reconhecimento e condições de trabalho de fato humanizadas.

\section{Uma experiência de extensão-investigação e a fundamentação teórica para sua análise preliminar}

32 A experimentação de ExtUniv, que conta com a participação de trabalhadores da Saúde de diversas profissionalidades, tem visado a criação de meios - inclusive a ação de um terceiro polo, ético-epistêmico - para, através do diálogo sinérgico intersaberes, produzir e desenvolver tais saberes (inclusive sobre o próprio trabalho) e, no processo, promover saúde (mental).

33 No processo de intervenção, em 2018 apareceu- trazida por profissionais de um setor ligado à Estratégia de Saúde da Família (ESF) [3] de um dos municípios do território do CEREST - inicialmente a encomenda para que o foco fosse a melhor compreensão da questão da violência e suas repercussões no trabalho. Buscou-se colocar em análise essa encomenda (análise cujo processo foge ao escopo do artigo), transformando-a em demanda. A proposta foi aceita e o modo de funcionamento foi fruto de acordo com os atores pertinentes.

Esses Encontros (EsT, nos quais ocorrem Conversas sobre o Trabalho, CsT) aconteceram (com algumas pausas nos períodos de férias) presencialmente, com periodicidade mensal, de julho de 2018 até fevereiro de 2020, quando foram interrompidos exatamente por causa da pandemia de COVID-19. Os contatos e as trocas de materiais pertinentes com o grupo se mantêm por meio de aplicativo de telefone, porém sem programação definida e sem regularidade.

Entendemos que foram oportunidades singulares para emergência de questões relativas às atividades de cada um(a) ali presente, debates sinérgicos, deliberações coletivas, aprendizagens mútuas, contribuições recíprocas e encaminhamentos férteis na produção de conhecimento sobre o trabalho e na luta pela saúde (mental) no trabalho.

Alguns resultados podem ser citados: (i) discussão e elaboração de um documento destinado ao nível central de gerenciamento buscando informações sobre as formas de adoecimento dos profissionais da Saúde daquele município; (ii) ações intersetoriais como, por exemplo, a participação em eventos do Departamento de Humanização ; (iii) participação de representantes dos usuários no Conselho Municipal de Saúde, o que abriu um importante canal de interlocução dos trabalhadores(as) com esse segmento.

Aproximando-nos do campo de questões que estarão em análise, registre-se que a partir de agosto de 2020 foi iniciada uma interlocução com um grupo específico de profissionais da ESF (dentre os quais alguns que já antes participavam do processo), os chamados "apoiadores" das equipes de Saúde da Família. Suas ações são de apoio institucional e/ou técnico às equipes da linha de frente da ESF. No curso de suas atividades de trabalho vinham surgido questões relativas às relações entre saúde mental e trabalho, frente às quais relataram estar tendo dificuldades para lidar, já há algum tempo. Para alguns participantes, este quadro teria se intensificado por conta da pandemia. Muitas das situações já relatadas passaram a estar presentes no cotidiano de trabalho desses profissionais, trazendo-lhes dificuldades adicionais para o exercício de suas atividades. 
Aceito o convite-encomenda-demanda e, considerando todo o processo até então já desenvolvido, entendemos que, metodologicamente, o dispositivo "Encontros sobre o Trabalho" (EsT) poderia ser também buscado com esse grupo, mesmo que na modalidade virtual, à distância. Como dispositivo seria possível efetuar uma análise coletiva sobre as atividades dos "apoiadores", os processos de trabalho envolvidos e suas formas de gerenciamento e gestão. Seria possível, na dinâmica dos Encontros, fazer o levantamento e análise das questões, das dificuldades e temas de interesse dos participantes, definindo em conjunto as ações futuras. A proposta foi bem recebida pelo grupo, tendo alguns revelado mesmo seu entusiasmo com a oportunidade de poderem ser ouvidos e também eles, "apoiados".

Até novembro de 2020 foram realizados quatro EsT remotos, por meio de plataforma de reuniões virtuais. Avalia-se a possibilidade de unir os dois grupos (o mais heterogêneo/ diversificado, com profissionais de diversos setores da área da Saúde, e o grupo dos "apoiadores" e técnicos da ESF) nos Encontros remotos seguintes. E, em seguida, promover outras formas de ação, tendo como perspectiva uma proposta de formação continuada, nos moldes do paradigma proposto por Teiger e Lacomblez (2013), por elas denominado "formação de atores na e pela análise do trabalho, para e pela ação".

Alguns disseram sentir falta de conhecimentos e técnicas que lhes permitissem melhor compreender e intervir sobre as questões que emergem nas Equipes a que dão apoio. Porém, quanto a isso, foi destacada a atuação positiva e propositiva de uma colega, também "apoiadora" do Núcleo de Apoio Institucional da ESF, como se verá.

De acordo com a perspectiva ergológica (Schwartz, 2000), propôs-se que fosse feito o convite para que ela apresentasse para o debate o que faz, como faz, quais suas questões, suas dificuldades, seus êxitos, o que permitiria dar maior visibilidade e colocar em análise suas estratégias, consideradas eficazes, inventivas e criativas pelos seus pares. Sabe-se o quanto se trata de um tipo de tarefa difícil, podendo até mesmo tornar-se angustiante. Aceito o convite, o EsT com a equipe do Núcleo de Apoio Institucional (NAI) foi divulgado, gerando interesse revelado por profissionais que atuam em outros setores da ESF (do Núcleo de Apoio à Saúde da Família e da Equipe de Educação Permanente), que começaram a participar, ampliando o grupo inicial.

Assim passou-se a proceder : em um Encontro seriam apresentados e discutidos casos e situações de trabalho por eles escolhidos, no Encontro seguinte haveria uma reflexão proposta e mediada pela equipe de ExtUniv, trazendo conteúdo teórico e metodológico sobre o que fora apresentado e discutido. As pistas que surgem apontam um caminho, a ser avaliado e eventualmente validado. Vários profissionais relataram experiências suas com as equipes às quais prestam o apoio técnico e, que no seu entendimento, poderiam ser consideradas exitosas. Como exemplo pode-se citar uma oficina em que uma profissional do NAI utilizou um instrumento denominado "baralho de valores" para discutir com uma equipe um problema sobre a agenda de marcação de consultas. Outro exemplo refere-se ao uso da Cartilha elaborada pela equipe de ExtUniv (Souza et al., 2020) por um profissional do NASF. Ele a utilizou como meio para promover um debate acerca da saúde mental no trabalho com uma equipe da ESF de uma unidade onde uma funcionária falecera recentemente. 


\section{A questão do abandono das regras profissionais articulado à vivência do medo} mudança de comportamento de alguns colegas profissionais de saúde, quanto aos incontornáveis cuidados para lidar com a COVID-19, que se tornaram regra da profissão. Ele verificou que alguns deles estavam sendo menos cuidadosos com o rigor dos protocolos e com o uso dos equipamentos de proteção individual (EPIs). Indagou então a si próprio e ao grupo, no Encontro: estaria havendo o que ele denominou "rotinização", entendida por ele como um "relaxamento geral" ? Ou seja, a prática nociva de uma certa naturalização ou acomodação com o que vem ocorrendo, negativamente, durante a pandemia. Esse assunto provocou um debate inicial, e, devido ao limite de tempo para explorá-lo intensamente naquele dia, tornou-se um dos temas a ser debatido mais amplamente no EsT seguinte, quando ele pôde expor mais detalhadamente sua questão.

A regra profissional desenvolvida frente à pandemia pareceu-lhe estar passando para um segundo plano, deixando de ser o foco principal de atenção e cuidados. As questões relativas à prevenção, aos protocolos técnico-científicos, "minaram" e se estaria diante do já famoso "novo normal", ao que ele denominou "rotinização" que, enfim, vem sendo aceita como se fosse natural.

No entendimento geral, pista que foi desenvolvida analiticamente pela equipe de coordenação da ExtUniv, foi de que tal reação seria uma manifestação de medo, ansiedade, até mesmo angústia, em um contexto de ausência de avaliação do trabalho na pandemia e efetivo reconhecimento de seus esforços de contribuição. No limite, tem ocorrido até mesmo sua desvalorização, não obstante circule uma narrativa de que seriam heróis nesta crise.

pano de fundo, mostra-se evidente e chocante a influência negativa das questões políticas e econômicas que permeiam o processo. $O$ quanto elas têm limitado a atuação profissional, o quanto têm sido impedidos de trabalhar com qualidade. 0 quanto elas têm gerado "pré-ocupação" (Clot, 2010).

uestões que, no plano macro e micro, rebatem então: seja no que se refere às condições e formas de organização do trabalho, tanto no que diz respeito ao gerenciamento, quanto à gestão de si, no curso mesmo de suas atividades; seja no volume e intensificação do trabalho, assim como na quantidade de equipes para as quais os agentes em foco precisam dar apoio, suporte técnico e também outros tipos de apoio.

São também relatadas vivências de medo (e solidão), diretamente registradas nas discussões. No caso apresentado, ela aparece indiretamente, na forma de um perigoso relaxamento com os cuidados e autocuidados. Abordagens da Clínica do Trabalho foram então mobilizadas para orientar a análise preliminar e a intervenção no Encontro seguinte àquele em que tal temática foi apresentada e iniciada a discussão.

No caso da Psicodinâmica do Trabalho (PdT), tendo como campo empírico inicial a Construção Civil (anos 1970 e 80, na França) e a fundamental contribuição de Damien Cru (2014, Cru \& Dejours, 1987), Dejours (1987/1992, p. 63) afirmara, já em 1980, que "o medo constitui uma das dimensões da vivência dos trabalhadores". E que, sob seu domínio, podem desenvolver-se paradoxais sistemas defensivos coletivos, para além

Laboreal, Volume $17 \mathrm{~N}^{\circ} 1$ | 2021 
dos mecanismos individuais, insuficientes para dar conta do medo gerado no trabalho, dado seu caráter particular e interiorizado. Em seguida, a PdT avançou registrando que haveria ao menos dois tipos de sistemas defensivos. Os de tipo estratégico seriam capazes de identificar as fontes do perigo gerador do medo, colaborando para alterá-la, quiçá anulá-la, sendo sustentados via consenso entre os membros de um coletivo de trabalho. Outra modalidade, em alguma medida também protetora (sendo muitas vezes a única forma defensiva encontrada pelos coletivos de trabalho), foi denominada ideologia ocupacional defensiva, que busca lidar com o medo negando-o, ocultando-o, ao menos o atenuando. Na Construção Civil francesa Cru e Dejours detectaram inclusive a ação nefasta de "jogos perigosos" (Dejours, 1987/ 1992), ludicamente utilizados para testar e eventualmente excluir os novatos considerados inaptos pelo coletivo de trabalho. Um ritual de expiação e purificação, em que se destaca a figura do bode expiatório - entendido aqui como tudo (como o uso de EPIs) e todos (por exemplo, os colegas que manifestam sentir medo) que façam alusão aos perigos reais (de contaminações, acidentes etc.). Assim, nesta modalidade dita ideológica, pela negação, a fonte real de riscos pode vir a perenizar-se e aquilo e aqueles que seriam possíveis parceiros na construção de mudanças positivas são excluídos.

Na verdade, toda essa complexa operação é construída porque a vivência do medo pode tornar-se incompatível com o exercício das atividades de trabalho. A falta de controle do medo pode fazer com que o corpo desmorone. Supõe-se aqui que dessa forma se poderia entender o relaxamento das regras profissionais neste momento, a "rotinização" observada pelo profissional de "apoio". Os trabalhadores e coletivos de trabalho, sob domínio desta defesa de tipo ideológico frente ao medo, desenvolvem uma pseudociência dos perigos e pretendem, com sua negação, driblá-lo, como se fosse ela uma esperteza. Pior, quando tal perigosa defesa é acionada, ela mesma se torna alvo de sua própria defesa, na forma de uma ideologia, programa de ação coletiva. A imprudência marca então o trabalhar. Como forma de controle do medo, ignoram-se os riscos. Assim, os perigos (acidentes, adoecimentos) reinam, quando inexistem os saberes de prudência, que são constitutivos dos coletivos profissionais em que reinam as regras de ofício (Cru \& Dejours, 1987 ; Cru, 2014).

51 Se a pista tiver consistência, na medida em que os próprios trabalhadores envolvidos nesta defesa ideológica tentam persuadir-se da sua pertinência, o próprio profissional que trouxe a questão e/ou outros colegas que façam críticas a tal procedimento pretensamente defensivo (equivocado e nocivo) poderiam vir a ser alvo de críticas até mesmo grosseiras, até mesmo violentas.

Desde os anos 1980, em companhia de Damiem Cru (2014), a relevância do patrimônio do ofício, das profissões, de suas regras -fruto de uma atividade deôntica, fazendo uso de sua língua própria- gera dentre outras riquezas protetivas os chamados saberes de prudência (Cru \& Dejours, 1987). Posteriormente, por outro lado, Dejours (1987/1992) assinala que a deterioração dos coletivos de trabalho, dada a falta de diálogo e visibilidade das ações, dada a desconfiança circulante, o silêncio gerado, assim como o isolamento e a solidão no trabalho podem, no contexto, ter efeitos devastadores, chegando até mesmo ao suicídio (Dejours \& Bègue, 2010), tanto sobre os sujeitos individualmente quanto sobre os coletivos de trabalho (agenciadores do engendramento e sustentação dos sistemas coletivos de defesa).

A proposta da PdT não passa pela diabolização e desmonte deste tipo de sistema ideológico, pois muitas vezes é a única forma encontrada por determinados coletivos de 
trabalho. A ação consequente seria a de colocá-la sob análise, contribuindo para sua transformação em estratégia defensiva.

54 A dimensão coletiva sendo tão decisiva, considera-se que as relações socioafetivas, inclusive no plano familiar, têm que ser incorporadas à análise. Aqui fica o registro de que não se trata de colocar as questões do trabalho restritas às tarefas e atividades de trabalho. Tanto a Ergologia quanto as diversas abordagens clínicas do trabalho mobilizadas no artigo vêm buscando desenvolvimento conceitual para dar conta do problema em foco, inclusive assumindo grande relevância a incontornável sinergia com o trabalho doméstico [4].

55 Ainda quanto à PdT, dentre suas diversas contribuições, Dejours (2004), ao apresentar o fenômeno que conceitua por "real do trabalho", colabora para nos fazer perceber o que se manifesta no campo social, afinal o trabalho tem sempre um destinatário (para o escopo do artigo, os clientes/usuários/pacientes), além dos familiares. Ou seja :

“O trabalho não é apenas uma atividade; ele é, também, uma forma de relação social, o que significa que ele se desdobra em um mundo humano caracterizado por relações de desigualdade, de poder e de dominação [...]. 0 real do trabalho, não é somente o real do mundo objetivo ; ele é, também, o real do mundo social" (Dejours, 2004, p. 31, grifo nosso).

Outra corrente das Clínicas do Trabalho que mobilizamos para análise e que destaca esta dimensão subjetiva é a Clínica da Atividade, que tem como maior referência Yves Clot (2010). Também em sua concepção, aquele(a) que trabalha, ao assumir seu posto, nunca se despoja inteiramente e de imediato de suas demais funções e atribuições sociais, em todos os planos. Clot (2010) registra ainda que outras "pré-ocupações", ligadas ao seu mundo do trabalho também podem emergir no curso de suas atividades correntes de trabalho, como o medo das formas de avaliação predominantes, do desemprego, etc.

\section{Considerações finais}

Outras pistas, para além da vivência do medo e dos sistemas defensivos de tipo ideológico, podem ser indicadas, exigindo desenvolvimento. Dentre outras, pode-se indagar: como dar conta de um quadro de infortúnios que vem emergindo na pandemia, com episódios em que diversos profissionais de saúde, por cautela, foram levados a passar mais tempo em seus locais de trabalho do que em suas residências? Alguns/algumas chegaram mesmo a morar provisoriamente em outro local, distante de seus familiares, assim exigindo novos gastos financeiros.

Como já foi destacado, a PdT registra que o trabalho tem uma dupla dimensão, numa das quais ("temporal"), ocorre a articulação com a história singular de quem trabalha, enquanto sujeito. Noutra dimensão ("espacial") destaca-se que os processos pertinentes ao trabalhar são vividos não só nas organizações em que se trabalha, também em relação dinâmica inclusive no espaço doméstico. Assim, considerando o atual quadro pandêmico, questões referentes às relações sociais de sexo / de gênero (Hirata, 2002), vêm emergindo com destaque e não podem tornar-se ponto cego de análise. $O$ lugar socialmente ocupado por profissionais do sexo feminino - que não deixam de ser filhas, esposas, mães - precisam entrar na análise. Além do que o trabalho de cuidados (como os de saúde) está em ressonância simbólica com as atividades de cuidados domésticos, 
no campo da reprodução (Hirata, 2002). Com relação à ressonância simbólica, Dejours afirma que o trabalhar :

"Exige condições muito particulares de concordância entre o teatro real e o teatro interno dos fantasmas e da história singular [...] é necessário que a tarefa tenha sentido para o sujeito, tendo em vista sua história singular" (Dejours, 1987/1992, p. 134)".

Sabe-se que, no contexto da pandemia, o incontornável trabalho doméstico vem sendo objeto de rearranjos significativos. Pelo que apontamos, além de ser uma segunda jornada de trabalho, a ausência das mulheres profissionais em seus lares gera um absenteísmo crítico na economia subjetiva familiar.

Coletivos familiares (inclusive de trabalho doméstico) e de trabalho profissional estão, portanto, em sinérgica operação. Diferentes normas e valores estão em relação dinâmica. Se toda prescrição tem sempre seus limites, no atual contexto de pandemia em que são elaborados e propostos novos e rígidos protocolos normativos, considerando esse quadro de incertezas inéditas, o debate de normas, revela-se mais do que nunca decisivo. O que exigiria a presença de coletivos de trabalho (inclusive os pertinentes à vida na família) estabilizados e em condições de lidar também com a profusão de valores que sempre circulam nas atividades de trabalho e nos debates de normas. Valores que se apresentam fortemente polarizados na atual conjuntura brasileira.

61 Considerando a imensa relevância da dimensão coletiva do trabalho, registra-se a riqueza do que geraram Clot e Faïta (2000), ao mobilizarem o conceito bakhtiniano de "gênero discursivo" para chegar ao conceito de gênero de ofício (Clot, 2010). Pode-se com ele ainda melhor compreender que, entre trabalho prescrito e o efetivamente realizado, aquele que trabalha nunca está só. Interpõem-se os gêneros profissionais, que são construções coletivas, patrimonializadas historicamente e culturalmente, incorporando acordos implícitos, e socialmente transmitidas pelos coletivos de trabalho. São eles que orientam e dão sustentação às atividades de um trabalhador que, como sinalizado, nunca está só em seu fazer cotidiano.

Importante registrar ainda que o que se conceitua como gênero profissional não é uma entidade inerte, estática. Frente ao movimento da vida (e do trabalho), com suas inovações e retrocessos, exige-se sempre a renovação. Ação cuja exigência é percebida e operacionalizada por quem trabalha, cuja análise é viabilizada através do conceito de estilo profissional (no interior do gênero).

63 Nesta mesma direção, buscando melhor compreender a operação coletiva, a Ergologia (Schwartz, 2007/2010) intervém com o conceito de "entidades coletivas relativamente pertinentes" (ECRPs). Do que se trata?

"Entidades" no sentido de que existem fronteiras invisíveis que englobam pessoas pertencentes a serviços diferentes, pessoas que se conhecem; "coletivas", tendo em vista que aí transitam informações - eventualmente nos dois sentidos, e pelas vias mais diversas [...]. Elas são "relativamente pertinentes" na medida em que são pertinentes para a compreensão de como as coisas andam, ao mesmo tempo são relativamente pertinentes, no sentido que as fronteiras são variáveis" (Schwartz, 2007/2010, p. 152).

64 Fica-nos o desafio de tentar nos aproximar cada vez mais dessas ECRP que se referem ao trabalhar na Saúde, o que implica conhecer seus territórios (geográfico, social e 
processual), seus ambientes e situações de trabalho, colocá-las em discussão e chegar a deliberações.

Não obstante todas as imensas dificuldades já citadas, o atual momento pandêmico, enquanto crise, pode ser uma oportunidade para serem colocadas em outro patamar algumas das questões presentes em nossa história recente, quiçá avançando na descoberta e proposição de mudanças positivas. Dentre outras questões, esperamos que o debate acerca do SUS e do campo da Saúde dos Trabalhadores (ST) poderá avançar e ganhar novos contornos.

Apesar de sua extrema relevância, o campo da Saúde dos Trabalhadores, em especial dos que atuam na Saúde Pública, vem sendo ainda timidamente abordada no Brasil, embora algumas iniciativas possam ser já encontradas.

Mas, para que um ciclo ascendente de desenvolvimento das profissões de saúde tome consistência, faz-se necessária também a constituição e/ou desenvolvimento de espaços públicos internos de expressão, discussão e deliberação (e de formação) sobre o trabalho (mesmo que de forma remota, considerando o atual momento).

Uma derradeira pista : quais as formas de avaliação do trabalho em curso, como estará se desenvolvendo a psicodinâmica do reconhecimento, para além de uma glorificação dos profissionais de saúde como heróis?

Enfim, considerando que, malgrado tantas adversidades, a vida segue no Brasil, revelase fundamental que se esteja atento às reservas de alternativas presentes no processo.

\section{BIBLIOGRAFIA}

Amarante, P., Amorim, A., Silva, J. P., Guljor, A. P., \& Machado, K. (2020). O enfrentamento do sofrimento psíquico na pandemia : diálogos sobre o acolhimento e a saúde mental em territórios vulnerabilizados. Rio de Janeiro : IdeiaSUS/Fiocruz.

Brito, J. (2005). Trabalho e Saúde Coletiva : o ponto de vista da atividade e das relações de gênero. Ciência \& Saúde Coletiva, 10(4), 879-890. https://doi.org/10.1590/

S1413-81232005000400012

Brito, J., \& Athayde, M. (2020). Comunidade Ampliada de Pesquisa-Intervenção : História do dispositivo e novas pistas. In I. Oddone et al (Orgs.), Ambiente do Trabalho (pp. 145-163). São Paulo : Hucitec.

Canguilhem, G. (1977). o problema da normalidade na história do pensamento biológico. In G. Canguilhem (Ed.), Ideologia e racionalidade nas ciências da vida. Lisboa : Edições 70.

Clot, Y. (2010). Trabalho e poder de agir. Belo Horizonte : Fabrefactum.

Clot, Y., \& Faïta, D. (2000). Genres et styles en analyse du travail : concepts et méthodes. Travailler, 4, 7-42.

Clot, Y., \& Lhuilier, D. (2013). Agir en Clinique du Travail. Paris : Érès.

Cru, D. (2014). Le risque et la règle. Paris : Érès. 
Cru, D., \& Dejours, C. (1987). Saberes de prudência nas profissões da Construção Civil. Revista Brasileira de Saúde Ocupacional, 15(59), 30-34.

Dejours, C. (1987/1992). A loucura do trabalho : estudo de psicopatologia do trabalho (5a edição). São Paulo : Cortez-Oboré.

Dejours, C. (2004). Subjetividade, trabalho e ação. Produção, 14(3), 27-34. https://doi.org/ 10.1590/S0103-65132004000300004

Dejours, C. (2012a). Trabalho vivo - Tomo I. Brasília : Paralelo 15.

Dejours, C. (2012b). Trabalho vivo - Tomo II. Brasília : Paralelo 15.

Dejours, C., \& Bègue, F. (2010). Suicídio e trabalho : o que fazer ? Brasília : Paralelo 15.

Diallo, M. D., \& Clot, Y.(2003). L'exploration de l'expérience dans l'analyse de l'activité : problèmes de méthode. L'orientation scolaire et professionnelle, 32(2), 203-217. https://doi.org/ $10.4000 /$ osp. 2720

Durrive, L. (2007/2010). Anexo ao capítulo 11 : Pistas para o ergoformador animar os encontros sobre o trabalho. In Y. Schwartz, \& L. Durrive (Orgs.), Trabalho e Ergologia : conversas sobre a atividade humana (pp. 309-318). Niterói : EdUFF.

Freire, P. (1968/2013). Extensão ou Comunicação ? (18 edição). Rio de Janeiro : Paz e Terra.

Gadotti, M. (2017). Extensão Universitária : Para quê ? Recuperado de https:// www.paulofreire.org/images/pdfs/Extens \%C3 \%A3o_Universit \%C3 \%A1ria__Moacir_Gadotti_fevereiro_2017.pdf.

Gramsci, A. (2000). Cadernos do cárcere - Antonio Gramsci : os intelectuais ; o princípio educativo ; jornalismo. Rio de Janeiro : Civilização Brasileira.

Guérin, F., Laville, A., F. Daniellou, J. Duraffourg, \& A. Kerguelen. (2001). Compreender o trabalho para transformá-lo : a prática da Ergonomia. São Paulo : Edgard Blücher.

Hirata, H. (2002). Nova divisão sexual do trabalho ? Um olhar voltado para a empresa e a sociedade. São Paulo : Boitempo Editorial.

Löwy, M. (2005). Walter Benjamin : aviso de incêndio : uma leitura das teses "sobre o conceito de história". São Paulo : Boitempo.

Masson, L. P., Gomes, L., \& Brito, J. (2015). Encontros sobre o trabalho : reflexões sobre o uso desta ferramenta metodológica em pesquisas em Unidades de Tratamento Intensivo Neonatais. Laboreal, 11(1). https://doi.org/10.4000/laboreal.4021

Noal, D., Passos, M. F., \& Freitas, C. M. (2020). Recomendações e orientações em saúde mental e atenção psicossocial na COVID-19. Rio de Janeiro : Fiocruz.

Oddone, I., Marri, G., Gloria, S., Briante, G., Chiatella, M., \& Re, A. (1986/2020). Ambiente de trabalho : a luta dos trabalhadores pela saúde (2ª edição). São Paulo : Hucitec.

Prigogine, I. (2001/2009). Ciência, razão e paixão. Belém : Eduepa.

Schwartz, Y. (2000). A comunidade científica ampliada e o regime de produção de saberes. Trabalho \& Educação, 7, 38-46.

Schwartz, Y. (2007/2010). A dimensão coletiva do trabalho e as Entidades Coletivas Relativamente Pertinentes (ECRP). In Y. Schwartz, \& L. Durrive (Orgs.), Trabalho \& Ergologia : conversas sobre a atividade humana (pp. 151-164). Niterói : EdUFF. 
Souza, W., Athayde, M., Azevedo, M., Valdrez, A., Sá, D., Alves, F., \& Queiroz, V. (2020). Trabalho e(m) saúde e a pandemia : contribuições da Psicologia para compreender, agir e transformar. Recuperado de http://www.psicologia.uerj.br/pdf/trabalho_saude_e_pandemia.pdf

Teiger, C., \& Lacomblez, M. (2013). (Se)Former pour transformer le travail : dynamiques des constructions d'une analyse critique du travail. Quebec/Bruxelas : Eds. PUL/ETUI.

\section{NOTAS}

1. Neste texto a palavra Saúde estará grafada com a inicial em maiúscula sempre que nos referirmos ao setor Saúde ou aos campos da Saúde Pública, Saúde Coletiva ou Saúde dos Trabalhadores.

2. Declaração feita em 7 de outubro de 2020 em coletiva de imprensa para lançamento de campanha do Ministério da Saúde, conforme noticiado em diversos veículos de comunicação. 0 SUS (Sistema Único de Saúde) é o sistema público de saúde brasileiro que, em sua concepção constitucional, está destinado a prestar serviços de saúde à população de forma gratuita, integral e universal.

3. A Estratégia Saúde da Família (ESF), anteriormente denominada Programa de Saúde da Família (PSF), é considerada pelo Ministério da Saúde (MS) como estratégia de expansão, qualificação e consolidação da atenção básica. Busca ampliar a resolutividade e o impacto na situação de saúde das pessoas e coletividades. Opera por intermédio de equipes multiprofissionais compostas minimamente por médico generalista ou especialista em Saúde da Família, enfermeiro generalista ou especialista em Saúde da Família, auxiliar ou técnico de enfermagem e agentes comunitários de saúde. Cada equipe deve ser responsável por, no máximo, 4.000 pessoas, sendo a média recomendada de 3.000 pessoas.

4. Cabe assinalar que, neste momento de pandemia, para algumas pessoas, principalmente para as mulheres, intensificaram-se as tarefas domésticas e as atividades de cuidados com os filhos e outros familiares.

\section{RESUMOS}

O artigo apresenta uma análise inicial de questões referentes ao trabalho em Saúde no Brasil, no contexto da pandemia da COVID-19, buscando contribuir para um debate acerca das relações entre o processo de trabalho, a dinâmica psicológica aí em curso e a luta pela saúde. Baseia-se em um referencial da Psicologia do Trabalho e Organizacional, orientado pelo ponto de vista da atividade e da experiência, para dar conta de materiais emergentes de uma experimentação que vem sendo desenvolvida no âmbito da "Extensão Universitária", sob a coordenação dos dois autores do artigo. Inicialmente, apresenta-se o quadro de emergência internacional da COVID-19 e características gerais das situações de trabalho que vêm sendo enfrentadas por profissionais da Saúde. Em seguida, selecionado um eixo principal como objeto de atenção, opera-se a análise de algumas das situações de trabalho, presentes nesse dramático contexto, que permitiram apresentar algumas pistas, a título de conclusão. 
El artículo presenta un análisis inicial de cuestiones relativas al trabajo en Salud en Brasil, en el contexto de la pandemia del COVID-19, buscando contribuir al debate sobre las relaciones entre el proceso de trabajo, la dinámica psicológica en curso y la lucha por la salud. Se basa en un referente de la Psicología del Trabajo y Organizacional, guiado desde el punto de vista de la actividad y la experiencia, a dar cuenta de materiales emergentes de un experimento que se viene desarrollando en el ámbito de la "Extensión Universitaria", bajo la coordinación de los dos autores del artículo. Inicialmente, se presenta el escenario de emergencia internacional del COVID-19 y las características generales de las situaciones de trabajo a las que se están enfrentando los profesionales de la salud. A continuación, seleccionando un eje principal como objeto de atención, se lleva a cabo el análisis de algunas de las situaciones laborales, presentes en ese contexto dramático, lo que permitió presentar algunas pistas, a modo de conclusión.

L'article présente une première analyse des problèmes liés au travail de santé au Brésil, dans le scénario pandémique du COVID-19. Il veut ainsi contribuer au débat concernant les relations entre le processus de travail, la dynamique psychologique en cours et la lutte pour la santé. Il est basé sur un référentiel de la Psychologie du Travail et des Organisations, guidé par le point de vue de l'activité et de l'expérience, et veut rendre compte de matériaux qui ont émergé d'une expérience développée dans le cadre d'un programme d"' Extension Universitaire ", mené sous la coordination des deux auteurs. Dans un premier temps, l'article présente la situation d'urgence internationale du COVID-19 et les caractéristiques générales des situations de travail auxquelles les professionnels de la Santé ont été confrontés. Un axe principal est ensuite objet d'attention conduisant à l'analyse de certaines situations de travail, présentes dans ce contexte dramatique. Ceci a permis d'avancer quelques hypothèses, en guise de conclusion.

The paper presents an initial analysis of issues related to health work in Brazil, in the context of COVID-19 Pandemic, seeking to contribute to a debate about the relationships between work process, the ongoing psychological dynamics and the struggle for health. It is based on a framework of Work Organizational Psychology, guided by the point of view of the activity and experience, to account for materials emerging from an experiment that has been developed within the scope of "University Extension", under the coordination of the two authors of the paper. Initially, both the international emergency context of COVID-19 and general characteristics of the work situations that are being faced by health professionals are presented. Then, upon selection of a main axis as the object of attention, the analysis of some work situations, present in that dramatic context, is carried out, which allowed to present some clues, as conclusion.

\section{ÍNDICE}

Keywords: work, health, work clinics, ergology, COVID-19

Palavras-chave: trabalho, saúde, clínicas do trabalho, ergologia, COVID-19

Mots-clés: travail, santé, cliniques du travail, ergologie, COVID-19

\section{AUTORES}

\section{WLADIMIR FERREIRA DE SOUZA}

http://orcid.org/0000-0003-4908-3057

Universidade do Estado do Rio de Janeiro - Departamento de Psicologia Social e Institucional, R. 
São Francisco Xavier, 524, Maracanã - Rio de Janeiro/RJ. Telefone (21) 2334-0000 souzalandi@uol.com.br

\section{MILTON ATHAYDE}

http://orcid.org/0000-0002-1238-4377

Universidade do Estado do Rio de Janeiro - Departamento de Psicologia Social e Institucional, R. São Francisco Xavier, 524, Maracanã - Rio de Janeiro/RJ. Telefone (21) 2334-0000

athayde.milton@gmail.com 